\title{
The Efficacy of Etoposide on H9c2 Cardiomyoblasts Against Doxorubicin Induced Cardiotoxicity
}

Sara Shabana, Suad Aden, Nabeel Abdulrahman, Sadaf Riaz, Maiy Jaballah, Iman A. Mohamed and Fatima Mraiche*

College of Pharmacy, Qatar University, Qatar

\begin{abstract}
Background: Doxorubicin (DOX), a widely used anticancer drug, has been associated with cardiotoxicity. Recently, DOX-induced cardiotoxicity has been attributed to topoisomerase II (TOPII)- $\beta$ expression and activity. In our study, we investigated the effect of inhibiting TOPII in attenuating the DOX induced cardiotoxicity.

Method: H9c2 cardiomyoblasts were treated with 1 or $2 \mu \mathrm{M}$ DOX (+/-) $1 \mu \mathrm{M}$ ETO. Cardiotoxicity was assessed by examining cell viability using the MTT assay, hypertrophy of crystal violet stained cardiomyoblasts and ROS production.

Results: DOX induced a dose dependent increase in cardiotoxicity as indicated by the significant reduction in cell viability $(71.77 \pm 9.25 \% 2 \mu \mathrm{M}$ DOX vs. $100 \%$ control, $\mathrm{P}<0.05)$, ROS production and hypertrophy. Stimulation of $\mathrm{H} 9 \mathrm{c} 2$ cardiomyoblasts with both $2 \mu \mathrm{M}$ DOX and $1 \mu \mathrm{M}$ ETO did not show a significant difference in cell viability, ROS production or hypertrophy.

Conclusion: DOX induced cardiotoxicity in $\mathrm{H} 9 \mathrm{c} 2$ cardiomyoblasts was not exacerbated in the presence of $1 \mu \mathrm{M}$ ETO. This provides further support to using the combination of DOX and ETO, which is currently being done to treat advanced AIDS related sarcomas in the clinical setting.
\end{abstract}

Keywords: Doxorubicin; Etoposide; Topoisomerase II; Cardiomyocyte hypertrophy

\section{Introduction}

Doxorubicin (DOX), one of the most effective and used anthracyclines [1], has been used for several decades due to its potent broads spectrum antineoplastic activity [2]. DOX is heavily used to treat hematological malignancies such as multiple myeloma and hodgkin's lymphoma [3,4]. In addition, DOX has been used for the treatment of solid tumors like ovarian and breast cancer $[5,6]$. Despite the clinical application of DOX, it is well known to induce a dose-dependent cardiotoxicity, which limits its clinical usage [7]. DOX induced cardiotoxicity, early-onset or late onset, is characterized by a decline in left ventricular ejection fraction or the development of congestive heart failure [1]. In a retrospective analysis of three trials it has been demonstrated that $26 \%$ of all patients who receive a cumulative DOX dose of $\geq 550 \mathrm{mg} / \mathrm{m} 2$ develop DOX related congestive heart failure [8].

The underlying molecular mechanism of DOX induced cardiotoxicity remains unclear. Zhang et al. reported that chronic DOX exposure induces functional and structural changes in the mitochondria; manifested by mitochondrial damage and vacuolization [9]. In addition, DOX was found to induce alterations in cardiac myosin and is responsible for nuclear membrane disruption [10]. Previous reports have associated DOX induced cardiotoxicity with its ability to produce reactive oxygen species (ROS) $[11,12]$, which causes a release of iron and contributes to DNA damage and lipid peroxidation [13]. Recent reports have suggested that DOX-induced cardiotoxicity is mediated in part by topoisomerase II (TOPII) - $\beta$ expression and activity $[9,13,14]$. TOPII is an enzyme that uncoils the supercoiled double stranded DNA and contributes to DNA replication. Two isoforms of TOPII exist, TOPII-a and TOPII- $\beta$, which are expressed in different tissue. TOPII-a is expressed in proliferating tissues including the bone marrow, spleen, and tumor cells and TOPII- $\beta$ is expressed in adult mammalian cardiomyocytes [15]. Furthermore, an in vitro study showed that Dexrazoxane, which is the only approved iron-chelating agent to treat DOX induced cardiotoxicity, reduced the expression of TOPII- $\beta$ enzyme [14]. Another study demonstrated that TOPII- $\beta$ knockout mice had improved cardiac function compared to the control group [9]. In our study, we hypothesize that TOPII- $\beta$ contributes to DOX induced cardiotoxicity.

In our study we aimed to develop an in-vitro model in which DOX induces cardiotoxicity. In addition, we investigated the effect of inhibiting TOPII in attenuating DOX induced cardiotoxicity. Etoposide (ETO), a non-specific TOPII targeted anticancer drug and used in solid tumors such as lung cancer, lymphomas and sarcomas, was used in our study to inhibit TOPII [16]. Zhang et al. reported that ETO possess a time dependent degradation of both TOPII-a and TOPII- $\beta$, but with a greater effect on TOPII- $\beta$ [17]. In addition, we examined the cardiotoxic effect of co administering DOX and ETO.

\section{Materials and Methods}

This study was carried out at the College of Pharmacy, Qatar University, Doha, Qatar.

\section{Cell culture}

H9c2 myoblasts, a clonal cell line derived from the embryonic

*Corresponding author: Fatima Mraiche, College of Pharmacy, Qatar University, Doha, Qatar, Tel: +97444033333; E-mail: fatima.mraiche@qu.edu.qa

Received October 09, 2015; Accepted November 03, 2015; Published November 09, 2015

Citation: Shabana S, Aden S, Abdulrahman N, Riaz S, Jaballah M, et al. (2015) The Efficacy of Etoposide on H9c2 Cardiomyoblasts Against Doxorubicin Induced Cardiotoxicity. Anat Physiol 5: 186. doi:10.4172/2161-0940.1000186

Copyright: ( $) 2015$ Shabana S, et al. This is an open-access article distributed under the terms of the Creative Commons Attribution License, which permits unrestricted use, distribution, and reproduction in any medium, provided the original author and source are credited. 
Citation: Shabana S, Aden S, Abdulrahman N, Riaz S, Jaballah M, et al. (2015) The Efficacy of Etoposide on H9c2 Cardiomyoblasts Against Doxorubicin Induced Cardiotoxicity. Anat Physiol 5: 186. doi:10.4172/2161-0940.1000186

Page 2 of 5

BD1X rat heart tissue, were obtained from the European Collections of Cell Cultures (ECACC) and cultured in DMEM/F12 1:1 culture media supplemented with $10 \%$ FBS and $1 \%$ penicillin/streptomycin at $37^{\circ} \mathrm{C}$ in a humidified atmosphere $(95 \% \mathrm{O} 2-5 \% \mathrm{CO} 2)$. Upon becoming confluent, cells were seeded at a density of $2.0 \times 106$ cells per $35 \mathrm{~mm}$ culture dishes containing the 10\% FBS culture medium and cultured for 24 hours. The cells were then treated with 1 or $2 \mu \mathrm{M}$ DOX in the presence and absence of $1 \mu \mathrm{M}$ ETO for 48 hours in preparation for assessment of cell viability, hypertrophy or ROS production.

\section{Cell viability assay}

Cell viability assay was measured using the MTT (3-(4,5)-dimethylthiazo(-z-yl)-3,5-dipheyltetrazoliumromide) assay. The cells were plated at a density of 50,000 cells/well in 24 -well plates and allowed to adhere. Following treatment, $10 \mu \mathrm{l}$ of MTT stock solution $\left(5 \mathrm{mg} / \mathrm{ml}\right.$ ) were added to each well. After 4 hours of incubation at $37^{\circ} \mathrm{C}$, the media was aspirated, and the produced formazan was solubilized in $100 \mu$ dimethyl sulphoxide (DMSO). The absorbance was measured at $570 \mathrm{~nm}$ using Spectra Max M2 microplate reader.

\section{Measurement of cell surface area}

Cell surface area of $\mathrm{H} 9 \mathrm{c} 2$ cardiomyoblasts stained with crystal violet was measured following treatment. Briefly, H9c2 cardiomyoblasts were washed twice with $1 \times$ PBS following treatment and incubated in a solution of $4 \%$ formaldehyde at room temperature for 10 minutes. Excess formaldehyde was aspirated and cardiomyoblasts were washed and fixed in cold methanol for 20 minutes at room temperature. Excess methanol was aspirated and fixed cardiomyoblasts were stained using a solution of crystal violet (Sigma) for a further 20 minutes. The average cell area of 50-70 randomly selected cells was taken. Cells were visualized with an inverted microscope equipped with a monochrome digitalized camera using 10X magnification. Cell area was determined using the AxioVision Imaging Software (Carl Zeiss Micro-imaging, New York, NY).

\section{Reactive oxygen species activity}

ROS activity of $\mathrm{H} 9 \mathrm{c} 2$ cardiomyoblasts treated with the respective drug treatment groups were imaged using an inverted fluorescence microscope following incubation with DCFH-DA $(20 \mu \mathrm{M})$ for 10 minutes.

\section{Statistical analysis}

All values expressed are compared to control \pm SEM. Student $t$ test was used to compute differences between groups where a $\mathrm{P}<0.05$ was considered a significant difference. Data were analyzed using the Statistical Package for Social Sciences (SPSS Software) version 22.

\section{Results}

\section{DOX induces cardiotoxicity in H9c2 cardiomyoblasts}

To verify that concentration of DOX needed to induce cardiotoxicity in $\mathrm{H} 9 \mathrm{c} 2$ cardiomyoblasts, $\mathrm{H} 9 \mathrm{c} 2$ cardiomyoblasts were stimulated with 1 or $2 \mu \mathrm{M}$ of DOX for 48 hours and assessed for cell viability, hypertrophy and ROS production. Treatment with 1 or $2 \mu \mathrm{M}$ DOX for 48 hours resulted in cell death, with a significant increase following stimulation with $2 \mu \mathrm{M}$ DOX $(71.77 \pm 9.25$ vs. $100 \%$ control, $\mathrm{P}<0.05)$ (Figure 1A).

DOX induced cardiotoxicity has been associated with ROS production $[1,2]$. To verify the role of DOX in H9c2 cardiomyoblasts on ROS production, $\mathrm{H} 9 \mathrm{c} 2$ cardiomyoblasts were incubated with DCFH-DA and visualized under a fluorescent microscope. ROS production was evident in $\mathrm{H} 9 \mathrm{c} 2$ cardiomyoblasts simulated with 1 or 2 $\mu \mathrm{M}$ DOX compared to control. Cells treated with $2 \mu \mathrm{M}$ DOX had more fluorescence, which indicated more ROS production (Figure 1B).

H9c2 cardiomyoblasts treated with increasing concentrations of DOX were also assessed for hypertrophy. Stimulation of H9c2 cardiomyoblasts with 1 or $2 \mu \mathrm{M}$ DOX resulted in a significant increase in the relative area of $\mathrm{H} 9 \mathrm{c} 2$ cardiomyoblasts $(176.83 \pm 46.9 \% 2 \mu \mathrm{M}$ DOX vs. $100 \pm 15.43 \%$ control $)$ and $(157.53 \pm 32 \% 1 \mu \mathrm{M}$ DOX vs. $100 \pm 15.43 \%$ control) (Figure 1C).

\section{ETO decreases cell viability in H9c2 cardiomyoblasts in a dose dependent manner.}

To determine an ideal concentration of ETO, a non-specific TOPII inhibitor to co-adminsiter with DOX, H9c2 cardiomyoblasts were stimulated with 1 or $5 \mu \mathrm{M}$ ETO. Cell viability of H9c2 cardiomyoblasts stimulated with ETO $(1 \mu \mathrm{M}$ or $5 \mu \mathrm{M})$ for 48 hours was measured using the MTT assay. Both concentrations of ETO induced a significant level of cell death $(72.33 \pm 5.7 \% 1 \mu \mathrm{M}$ ETO vs. $100 \pm 15.43 \%$ control, $\mathrm{P}<0.005)$ and $(62.38 \pm 2 \% 5 \mu \mathrm{M}$ ETO vs. $100 \pm 15.43 \%$ control, $\mathrm{P}<0.05)$, with a greater amount of cell death induced with $5 \mu \mathrm{M}$ of ETO (Figure 2).

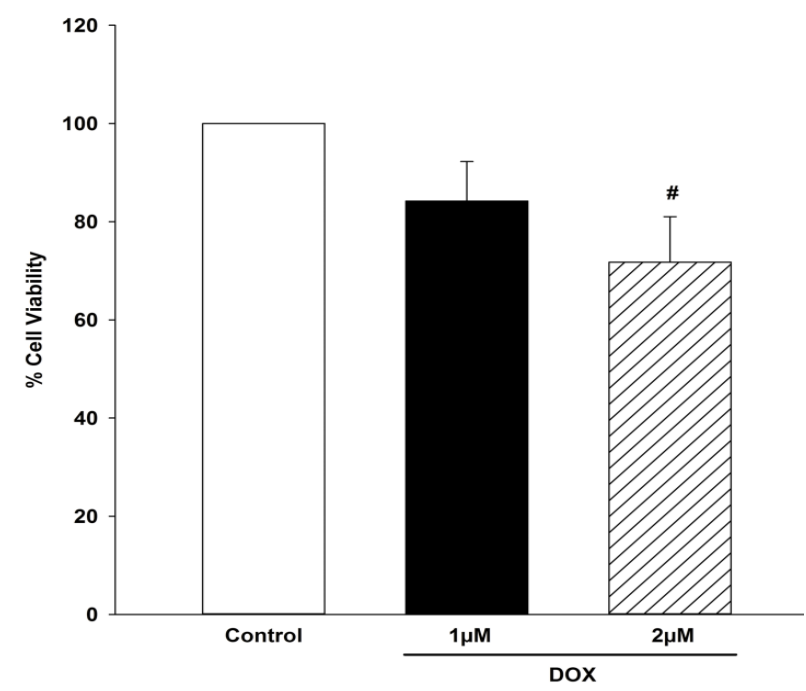

Figure 1A: Doxorubicin induces cardiotoxicity in $\mathrm{H} 9 \mathrm{c} 2$ cardiomyoblasts. H9c2 cardiomyoblasts were assessed for cell viability, hypertrophy and reactive oxygen species production (ROS) in the presence and absence of 1 $\mu \mathrm{M}$ or $2 \mu \mathrm{M}$. Doxorubicin (DOX) for 48 hours. Cell viability was assessed by MTT colorimetric assay in triplicates. Cell viability of $\mathrm{H} 9 \mathrm{c} 2$ cardiomyoblasts is expressed as a percentage of control $(P<0.05), n=6$.

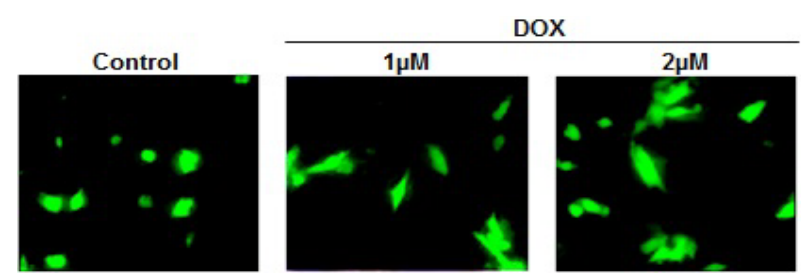

Figure 1B: Representative images of $\mathrm{H} 9 \mathrm{c} 2$ cardiomyoblasts stained with DCF and imaged under fluorescence microscopy for ROS production. 
Citation: Shabana S, Aden S, Abdulrahman N, Riaz S, Jaballah M, et al. (2015) The Efficacy of Etoposide on H9c2 Cardiomyoblasts Against Doxorubicin Induced Cardiotoxicity. Anat Physiol 5: 186. doi:10.4172/2161-0940.1000186

Page 3 of 5
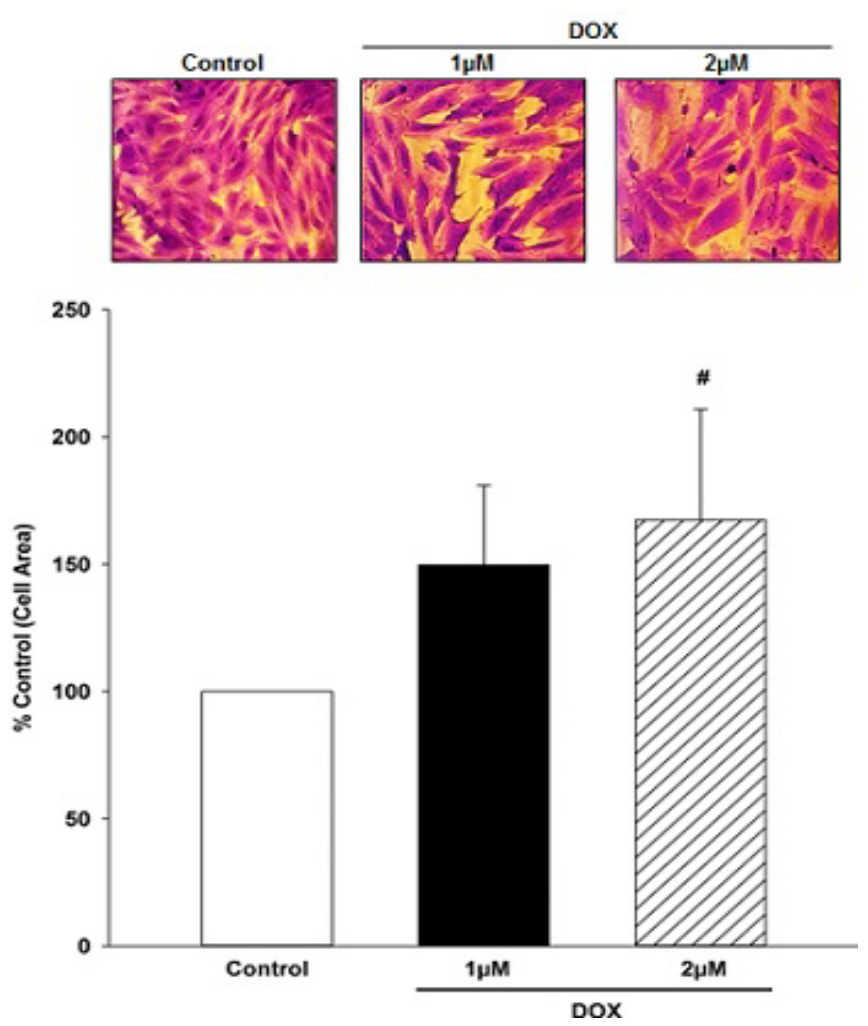

Figure 1C: Upper panel: representative images of $\mathrm{H} 9 \mathrm{c} 2$ cardiomyoblasts stained with crystal violet following stimulation with DOX, Lower panel: quantitative analysis of $\mathrm{H} 9 \mathrm{c} 2$ cardiomyoblast cell surface area. Results are expressed as a percentage of control, $\mathrm{n}=3 ; \mathrm{H}<0.05$.

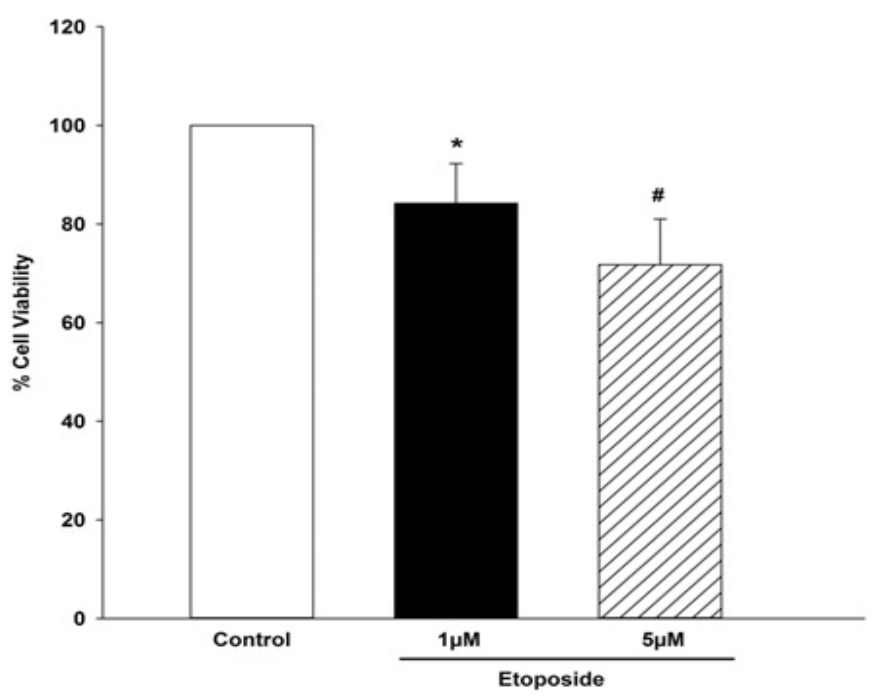

Figure 2: Etoposide decreases cell viability in a dose dependent manner. $\mathrm{H} 9 \mathrm{c} 2$ cardiomyoblasts were assessed for cell viability in the presence and absence of $1 \mu \mathrm{M}$ or $5 \mu \mathrm{M}$ of Etoposide (ETO) for 48 hours. Cell viability was assessed by MTT colorimetric assay in triplicates. Results are expressed as a percentage of control, $n=3-5$. $\# P<0.05,{ }^{*} P<0.005$.

\section{TOPII Inhibition with ETO Does not Attenuate DOX Induced Cardiotoxicity in H9c2 Cardiomyoblasts.}

To determine whether TOPII inhibition attenuates DOX induced cardiotoxicity in $\mathrm{H} 9 \mathrm{c} 2$ cardiomyoblasts, $\mathrm{H} 9 \mathrm{c} 2$ cardiomyoblasts were stimulated with $1 \mu \mathrm{M}$ ETO and $2 \mu \mathrm{M}$ DOX and assessed for cell viability, hypertrophy and ROS production Stimulation of H9c2 cardiomyoblasts for 48 hours with $1 \mu \mathrm{M}$ ETO and $2 \mu \mathrm{M}$ DOX did not show a further reduction in cell viability $(68.35 \pm 11.9 \%$ combination vs. $71.77 \pm 9.25 \% 2 \mu \mathrm{M}$ DOX) (Figure $3 \mathrm{~A}$ ). Similary, ROS generation of $\mathrm{H} 9 \mathrm{c} 2$ cardiomyoblasts stimulated with both $1 \mu \mathrm{M}$ ETO and $2 \mu \mathrm{M}$ DOX did not differ from the stimulation of H9c2 cardiomyoblasts with $2 \mu \mathrm{M}$ DOX alone (Figure 3B). Furthermore, the cell area of H9c2 cardiomyoblasts stimulated with both $1 \mu \mathrm{M}$ ETO and $2 \mu \mathrm{M}$ DOX did not induce a significant cell hypertrophic effect compared to $2 \mu \mathrm{M}$ DOX alone $(220.51 \pm 63.51 \%$ combination vs. $176.83 \pm 46.9 \% 2 \mu \mathrm{M}$ DOX) (Figure 3C).

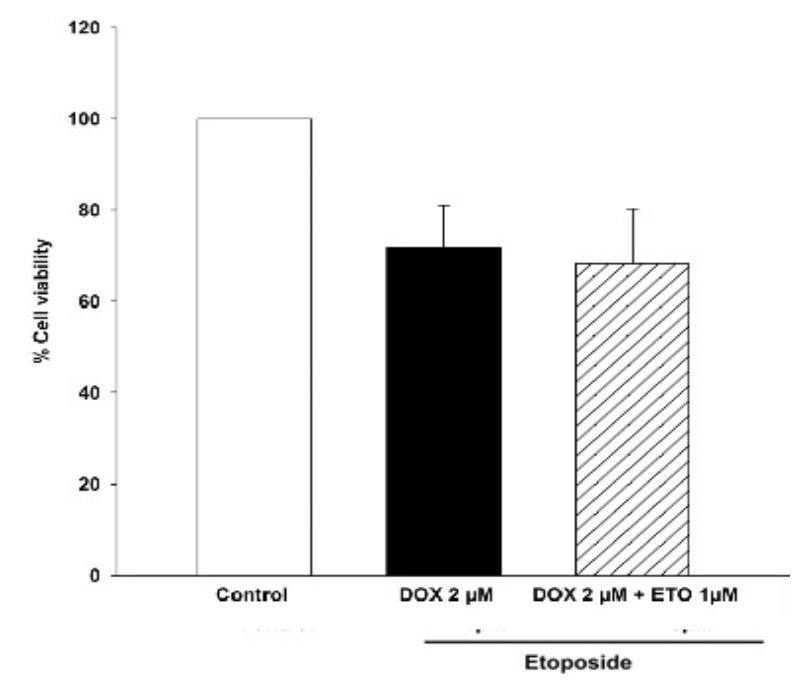

Figure 3A: Topoisomerase inhibition with Etoposide does not attenuate. Doxorubicin induced cardiotoxicity in $\mathrm{H} 9 \mathrm{c} 2$ cardiomyoblasts. H9c2 cardiomyoblasts were assessed for cell viability, hypertrophy and reactive oxygen species production (ROS) in the presence and absence of $1 \mu \mathrm{M}$ Etoposide (ETO) and $2 \mu \mathrm{M}$ Doxorubicin (DOX) for 48 hours. A. Cell viability was assessed by MTT colorimetric assay in triplicates. Cell viability of H9c2 cardiomyoblasts is expressed as a percentage of control $(P<0.05), n=5$.

B.
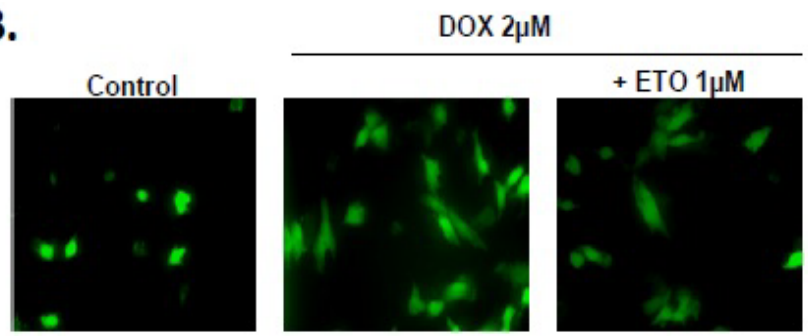

Figure 3B: Representative images of $\mathrm{H} 9 \mathrm{c} 2$ cardiomyoblasts stained with DCF and imaged under fluorescence microscopy for ROS production. 
Citation: Shabana S, Aden S, Abdulrahman N, Riaz S, Jaballah M, et al. (2015) The Efficacy of Etoposide on H9c2 Cardiomyoblasts Against Doxorubicin Induced Cardiotoxicity. Anat Physiol 5: 186. doi:10.4172/2161-0940.1000186

Page 4 of 5

c.

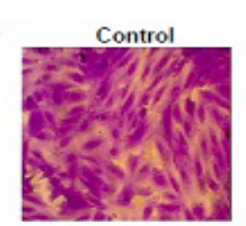

300

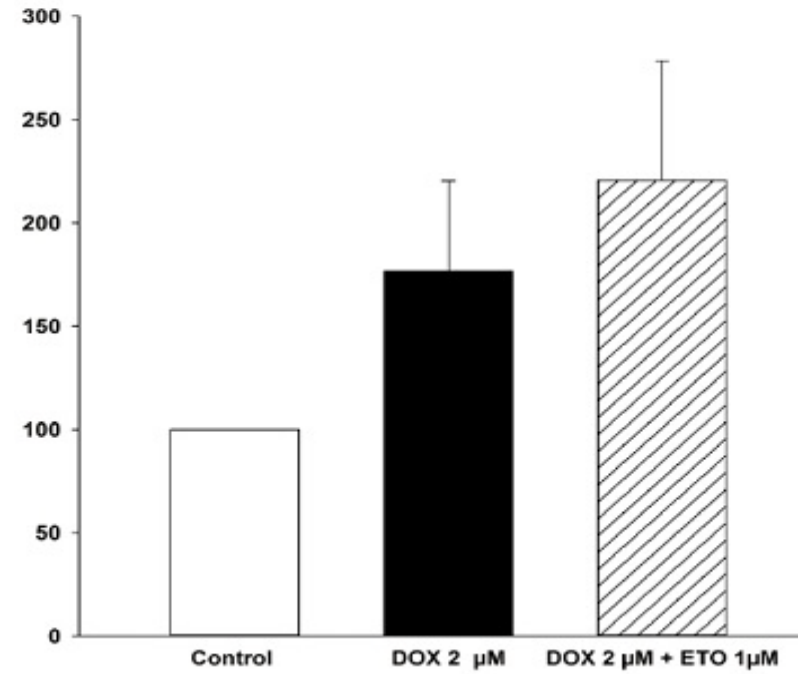

Figure 3C: Upper panel: representative images of $\mathrm{H} 9 \mathrm{c} 2$ cardiomyoblasts stained with crystal violet following stimulation with DOX, Lower panel: quantitative analysis of $\mathrm{H} 9 \mathrm{c} 2$ cardiomyoblast cell surface area. Results are expressed as a percentage of control, $n=3$.

\section{Discussion}

DOX is among the most effective and widely used antineoplastic agents. However, the use of DOX is restricted due to its ability to induce cardiotoxicity. Several studies have supported the role of ROS in DOX induced cardiotoxicity $[11,12]$. Recently, TOPII- $\beta$ expression has been associated with DOX induced cardiotoxicity $[9,13,14]$. In our study, we examined whether the inhibition of TOPII prevented the DOX induced cardiotoxicity. ETO, a cytotoxic anticancer drug which inhibits DNA synthesis by forming a complex with TOPII and DNA, was used in our study. In addition, our study examined the cardiotoxic effects of co-administering DOX and ETO.

In agreement with previous reports, the stimulation of $\mathrm{H} 9 \mathrm{c} 2$ cardiomyoblasts with DOX resulted in a significant reduction in cell viability, induced ROS production and resulted in a hypertrophic phenotype [10,17]. ETO, a cytotoxic anticancer drug which inhibits DNA synthesis by forming a complex with TOPII, was used in this study as a means to inhibit TOPII. ETO is used mainly in the treatment of refractory testicular tumors and for the treatment of small-cell lung carcinoma and has been associated with hypotension [18]. In vitro, Hsiao et al. demonstrated that $10 \mu \mathrm{M}$ of ETO inhibited the cell growth of H9c2 cardiomyoblasts by 55\% [19-21]. In our study, ETO decreased the cell viability of $\mathrm{H} 9 \mathrm{c} 2$ cardiomyoblasts in a dose dependent manner with a greater decrease in cell viability with increasing concentrations of ETO.

TOPII- $\beta$ mRNA is predominantly expressed in the myocardium of adult mice [22]. These findings suggest that DOX mediated targeting of TOPII- $\beta$ could contribute to its cardiotoxic side effects. We are the first to demonstrate that combining ETO $(1 \mu \mathrm{M})$, a TOPII inhibitor, with
DOX $(2 \mu \mathrm{M})$ does not attenuate DOX induced cardiotoxicity. ETO failed to show any significant effect on reducing the cardiotoxic effects of DOX in H9c2 cardiomyoblasts. The inability of ETO to regress the DOX induced cytotoxic effect could be attributed to the fact that ETO is a nonselective TOPII- $\beta$ inhibitor [5]. ETO inhibits both TOPII isoforms (TOPII-a and TOPII- $\beta$ ), which are regulated very differently $[15,22-24]$. Further studies investigating the use of specific TOPII- $\beta$ inhibitors on DOX-induced cardiotoxicity is needed to verify the role of TOPII on DOX-induced cardiotoxicity.

Although both DOX and ETO are cytotoxic anticancer agents, the combination of both agents did not cause a significant reduction in cell viability or change in cell size when compared to H9c2 cardiomyoblasts treated with DOX alone. This was surprising to observe since the presence of two anticancer agents is predicted to result in more cell destruction. In addition, ETO similar to DOX has also been demonstrated to induce cardiotoxic effects. It has been demonstrated that patients who have previously undergone chemotherapy or mediastinal radiation may be at increased risk for MI following ETO treatment [19]. The concomitant chemotherapy of ETO with other agents has also been shown to be a predisposing factor for MI [20]. This observation emphasized that combing ETO with DOX does not further deteriorate $\mathrm{H} 9 \mathrm{c} 2$ cardiomyoblasts. This also provides further support to using the combination of DOX and ETO, which is being done to treat advanced AIDS related sarcoma $[25,26]$.

In our study, we have demonstrated that DOX induced a dose dependent increase in cardiotoxicity in $\mathrm{H} 9 \mathrm{c} 2$ cardiomyoblasts, with a greater cardiotoxic response upon treatment with $2 \mu \mathrm{M}$ DOX. 1 $\mu \mathrm{M}$ ETO, a TOPII inhibitor, did not further attenuate this DOX induced cardiotoxicity. Interestingly, the combination of ETO and DOX did not further deteriorate the hypertrophic phenotype of $\mathrm{H} 9 \mathrm{c} 2$ cardiomyoblasts. The idea that TOPII targeting is involved in doxorubicin induced cardiotoxicity has significant clinical implications. Further studies are needed to investigate the role of TOPII- $\beta$ as a possible cardioprotective target.

\section{Conflicting Interests}

'The author(s) declare that they have no competing interests'.

\section{Acknowledgements}

This work was supported by the Qatar University Research Office (QUSTCPH-FALL-13/14-1), Qatar University, Doha, Qatar. The funders had no role in the study design, data collection and analysis, decision to publish, or preparation of the manuscript.

\section{Authors Contributions}

SS, SA, NA, SR, MJ and IAM carried out the in vitro experiments, SS, SA and FM drafted the manuscript. FM participated in the design of the study. SS, SA an NA performed the statistical analysis. FM conceived of the study, and participated in its design and coordination and helped to draft the manuscript. All authors read and approved the final manuscript.

\section{Authors Information}

FM: PhD, Assistant Professor and Chair of Pharmaceutical Sciences Section; SS and SA: BSc Pharm Candidates; NA: MSc, Research Associate; MJ: PhD Candidate and Research Assistant; IAM, MSc.

\section{References}

1. Yeh ET, Bickford CL (2009) Cardiovascular complications of cancer therapy: incidence, pathogenesis, diagnosis, and management. J Am Coll Cardiol 53: 2231-2247.

2. Benjamin RS (1978) Adriamycin and other anthracycline antibiotics under study in the United States. Recent Results Cancer Res 63: 230-240.

3. Ludwig H, Strasser-Weippl K, Schreder M, Zojer N (2007) Advances in the 
Citation: Shabana S, Aden S, Abdulrahman N, Riaz S, Jaballah M, et al. (2015) The Efficacy of Etoposide on H9c2 Cardiomyoblasts Against Doxorubicin Induced Cardiotoxicity. Anat Physiol 5: 186. doi:10.4172/2161-0940.1000186

Page 5 of 5

treatment of hematological malignancies: current treatment approaches in multiple myeloma. Ann Oncol 18 Suppl 9: 64-70.

4. Ansell SM, Armitage J (2005) Non-Hodgkin lymphoma: diagnosis and treatment. Mayo Clin Proc 80: 1087-1097.

5. Maluf FC, Spriggs D (2002) Anthracyclines in the treatment of gynecologic malignancies. Gynecol Oncol 85: 18-31.

6. Gogineni K, DeMichele A (2012) Current approaches to the management of Her2-negative metastatic breast cancer. Breast Cancer Res 14: 205.

7. Von Hoff DD, Layard MW, Basa P, Davis HL Jr, Von Hoff AL, et al. (1979) Risk factors for doxorubicin-induced congestive heart failure. Ann Intern Med 91: 710-717

8. Swain SM, Whaley FS, Ewer MS (2003) Congestive heart failure in patients treated with doxorubicin: a retrospective analysis of three trials. Cancer 97 2869-2879.

9. Zhang S, Liu X, Bawa-Khalfe T, Lu LS, Lyu YL, et al. (2012) Identification of the molecular basis of doxorubicin-induced cardiotoxicity. Nat Med 18: 1639-1642.

10. Sardão VA, Oliveira PJ, Holy J, Oliveira CR, Wallace KB (2009) Morphological alterations induced by doxorubicin on $\mathrm{H} 9 \mathrm{c} 2$ myoblasts: nuclear, mitochondrial, and cytoskeletal targets. Cell Biol Toxicol 25: 227-243.

11. Simůnek T, Stérba M, Popelová O, Adamcová M, Hrdina R, et al. (2009) Anthracycline-induced cardiotoxicity: overview of studies examining the roles of oxidative stress and free cellular iron. Pharmacol Rep 61: 154-171.

12. Xu X, Persson HL, Richardson DR (2005) Molecular pharmacology of the interaction of anthracyclines with iron. Mol Pharmacol 68: 261-271.

13. Ky B, Vejpongsa P, Yeh ET, Force T, Moslehi JJ (2013) Emerging paradigms in cardiomyopathies associated with cancer therapies. Circ Res 113: 754-764.

14. Lyu YL, Kerrigan JE, Lin CP, Azarova AM, Tsai YC, et al. (2007) Topoisomerase Ilbeta mediated DNA double-strand breaks: implications in doxorubicin cardiotoxicity and prevention by dexrazoxane. Cancer Res 67: 8839-8846.

15. Turley H, Comley M, Houlbrook S, Nozaki N, Kikuchi A, et al. (1997) The distribution and expression of the two isoforms of DNA topoisomerase II in normal and neoplastic human tissues. Br J Cancer 75: 1340-1346.

16. Bender R, Osheroff N (2008) DNA topoisomerases as targets for the chemotherapeutic treatment of cancer. Cancer Drug Discovery and Development pp 57-91.

17. Zhang A1, Lyu YL, Lin CP, Zhou N, Azarova AM, et al. (2006) A protease pathway for the repair of topoisomerase II-DNA covalent complexes. J Biol Chem 281: 35997-36003.

18. Cohen MH, Broder LE, Fossieck BE, Ihde DC, Minna JD (1977) Phase clinical trial of weekly administration of VP-16-213 in small cell bronchogenic carcinoma. Cancer Treat Rep 61: 489-490.

19. Schecter JP, Jones SE, Jackson RA (1975) Myocardial infarction in a 27-yearold woman: possible complication of treatemtn with VP-16-213 (NSC-141540), mediastinal irradiation, or both. Cancer Chemother Rep 59: 887-888.

20. Airey CL, Dodwell DJ, Joffe JK, Jones WG (1995) Etoposide-related myocardial infarction. Clin Oncol (R Coll Radiol) 7: 135.

21. Hsiao CJ, Li TK, Chan YL, Hsin LW, Liao CH et al. (2008) WRC-213, an I-methionine-conjugated mitoxantrone derivative, displays anticancer activity with reduced cardiotoxicity and drug resistance: identification of topoisomerase II inhibition and apoptotic machinery in prostate cancers. Biochem Pharmacol. 75: 847-856.

22. Capranico G, Tinelli S, Austin CA, Fisher ML, Zunino F (1992) Different patterns of gene expression of topoisomerase II isoforms in differentiated tissues during murine development. Biochim Biophys Acta 1132: 43-48.

23. Tsutsui K, Tsutsui K, Okada S, Watanabe M, Shohmori T, et al. (1993) Molecular cloning of partial cDNAs for rat DNA topoisomerase II isoforms and their differential expression in brain development. J Biol Chem 268: 1907619083.

24. Watanabe M, Tsutsui K, Tsutsui K, Inoue Y (1994) Differential expressions of the topoisomerase II alpha and II beta mRNAs in developing rat brain. Neurosc Res 19: 51-57.
Citation: Shabana S, Aden S, Abdulrahman N, Riaz S, Jaballah M, et al. (2015) The Efficacy of Etoposide on $\mathrm{H} 9 \mathrm{c} 2$ Cardiomyoblasts Against Doxorubicin Induced Cardiotoxicity. Anat Physiol 5: 186. doi:10.4172/2161-0940.1000186

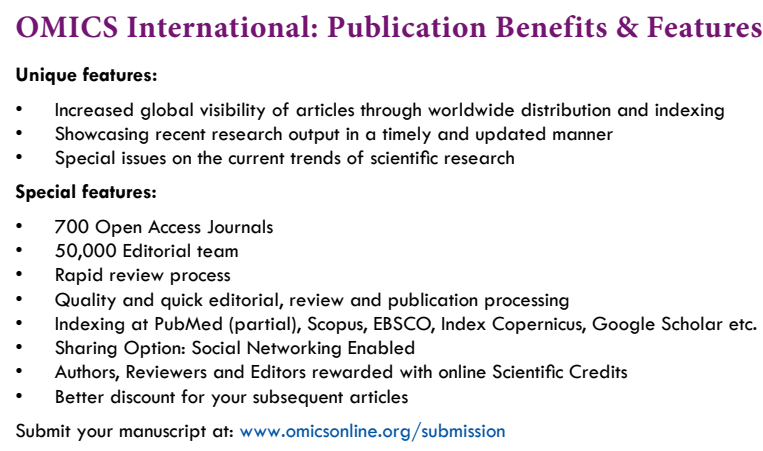

OMICS International: Publication Benefits \& Features

Showcasing recent research output in a timely and updated manner

ss Journo

50,000 Editorial team

Soogle Scholar etc.

Option: Social Networking Enabled

Submit your manuscript at: www.omicsonline.org/submission 